\title{
RESEARCH
}

Open Access

\section{Recreational off-highway vehicle crashes resulting in victims being treated at a regional trauma center: mechanisms and contributing factors}

\author{
Charles A. Jennissen ${ }^{1,2^{*}}$, Meaghan T. Reaney ${ }^{2 \dagger}$ and Gerene M. Denning ${ }^{1+}$
}

From 24th Annual Injury Free Coalition for Kids Conference: Forging New Frontiers: Motor Vehicle Safety for All Ages Fort Lauderdale, FL, USA. 06-08 December 2019

\begin{abstract}
Background: Recreational off-highway vehicles (ROVs) have become increasingly popular in recent years; however, crash epidemiology is not well described. ROVs travel at least $30 \mathrm{mph}$, and unlike all-terrain vehicles, have a rollover protective structure (ROPS) and seat belts or a harness system for occupants. This study's objective was to evaluate the demographics, mechanisms, injuries, and associated risk factors of ROV crashes.

Methods: A retrospective chart review was performed for patients of all ages with ROV-related injuries presenting to a Level 1 trauma center from 2004 to 2017. Cases were identified by ICD-9/10 codes and narrative searches. Person- and crash-related variables were examined in relation to injury outcomes including body area injured, injury severity score, and disposition (e.g. hospitalization, intensive care unit admission). Descriptive, bivariate (chi-square, Fishers exact test), and linear regression analyses were performed.

(Continued on next page)
\end{abstract}

\footnotetext{
* Correspondence: charles-jennissen@uiowa.edu

${ }^{\dagger}$ Charles A. Jennissen, Meaghan T. Reaney and Gerene M. Denning

contributed equally to this work.

'Department of Emergency Medicine, Roy J. and Lucille A. Carver College of

Medicine, University of lowa, lowa City 52242, USA

${ }^{2}$ Department of Pediatrics, Roy J. and Lucille A. Carver College of Medicine,

University of lowa, lowa City 52242, USA
}

(c) The Author(s). 2020 Open Access This article is licensed under a Creative Commons Attribution 4.0 International License, which permits use, sharing, adaptation, distribution and reproduction in any medium or format, as long as you give appropriate credit to the original author(s) and the source, provide a link to the Creative Commons licence, and indicate if changes were made. The images or other third party material in this article are included in the article's Creative Commons licence, unless indicated otherwise in a credit line to the material. If material is not included in the article's Creative Commons licence and your intended use is not permitted by statutory regulation or exceeds the permitted use, you will need to obtain permission directly from the copyright holder. To view a copy of this licence, visit http://creativecommons.org/licenses/by/4.0/. The Creative Commons Public Domain Dedication waiver (http://creativecommons.org/publicdomain/zero/1.0/) applies to the data made available in this article, unless otherwise stated in a credit line to the data. 
(Continued from previous page)

Results: Seventy-two patients with ROV-related injuries were identified. The number of injured patients increased over the study period $(p<0.01$ ). Patients were $49 \%$ youth < 16 years old, $63 \%$ males, and $99 \%$ Caucasian. Half of the injured (51\%) were passengers, with a higher proportion of youth being passengers (70\%) as compared to adults (35\%) ( $p<0.01$ ). Nearly one-third (30\%) of crash victims < 16 years old were ROV drivers. Twenty-nine percent of all crashes occurred on roadways. Almost $40 \%$ of injured adults crashed at night, while all youth were injured during the day $(p<0.01)$. The primary crash mechanism was a rollover (67\%). Only one patient was documented as being helmeted, and approximately one-fourth (24\%) sustained head injuries and/or loss of consciousness. Other documented injuries included those to the face (20\%), chest (22\%), abdomen (11\%), extremities (58\%), and skin (51\%). Over $90 \%$ of narratives were consistent with victims being unrestrained. Nearly three-fourths (74\%) of victims were hospitalized and 26\% required ICU care, one-half (53\%) of these being children.

Conclusions: Although ROVs have ROPs, lack of helmet and safety belt use are reducing their benefit. Youth are a large proportion of those injured in ROV crashes, often while driving despite vehicle operation recommended only for those $\geq 16$ years old. Increased public education is needed regarding proper safety measures while operating and riding ROVs.

Keywords: Recreational off-road vehicles, Utility task vehicles, Side-by-sides, Rollover, Safety belt, Harness, Helmet, Youth, Adolescent

\section{Background}

Recreational off-highway vehicles (ROVs) are off-road vehicles whose popularity has soared in recent years (U.S. Consumer Product Safety Commission, 2016). Since 2004, world-wide sales of ROVs have continually risen and reached 530,000 vehicles in 2018 (Polaris Industries, n.d.-a). Sales have surpassed that of all-terrain vehicles (ATVs) since 2015 (Polaris Industries, n.d.-a). Consequently, ROV-related deaths and injuries have become an emerging safety issue, particularly among children (Linnaus et al., 2017; Richardson et al., 2018).

ROV types include sport models primarily for recreation, and multipurpose vehicles for both recreational and occupational use. All ROVs have maximum speeds of at least 30 miles per hour (mph), and most can travel at highway speeds (Wilson, 2015). A related off-road vehicle is the utility task vehicle (UTV). ROVs are often referred to as UTVs, but the latter have maximum speeds of $\leq 25 \mathrm{mph}$ (Wilson, 2015).

ROVs are designed solely for off-road use having low pressure tires with knobby treads, and a relatively narrow track and high clearance, which increases their risk of rollover. They also have a steering wheel for directional control, foot pedals for acceleration and braking, and are designed to carry more than one passenger (unlike most ATVs) with bench or bucket seating. ROVs have a rollover protective structure (ROPS) with seat belts or harness restraints for each seating position. In addition, in contrast to most ATVs that have all wheels traveling at the same speed due to a solid rear axle or locked differential, the differential in many ROVs may be selectively unlocked. This allows the outer wheels to rotate faster than the inner wheels when traveling around a corner, similar to a roadway vehicle, and makes the vehicle less likely to tear up turf such as lawns.
Decades of research have provided a wealth of information with regards to ATV crashes and injuries. In contrast, there are very few published studies describing ROV crash and injury epidemiology. Identifying the factors involved in ROV crashes and their associated injuries is vital for developing injury prevention strategies. The objective of this study was to evaluate ROV-related injuries among patients presenting to a Level 1 trauma center.

\section{Methods}

\section{Patient population}

A retrospective chart review was performed for patients of all ages presenting to a Level 1 trauma center with ROVrelated injuries from January 1, 2004 to December 31, 2017. Patients were identified in the ED trauma patient database using International Classification of Diseases 9th edition (ICD-9) codes (E821.0-E821.9, E822.2, E823.0E823.3, E824.0, E824.1, E824.8, E825.0, E825.1-E825.9, E849.1) and 10th edition (ICD-10) codes (V84.5XXA, V86.09XA, V86.55XA, V86.59XA, V86.69XA, V86.79, V86.99XA, V89.1XXA, Y92.79, Y92.71). This study was approved by the authors' Institutional Review Board.

\section{Identification of ROV crashes}

The ICD codes include crashes of both ATVs and ROVs. To identify the latter, narratives were searched for the terms "ROV" and "UTV," vehicle makes/models, and mention of any of the following: steering wheel, foot pedals, seat belt, harness, front seat/back seat, more than 4 wheels, rollover protection structure (ROPS), roll cage, or roll bar.

Results from this approach identified 73 cases. Specific keywords found were "UTV" (45 cases), "Gator ${ }^{\mathrm{Tm}}$ " (7 cases), "Rhino ${ }^{\text {tu”" }}$ (1 case), "roll cage" (6 cases), "roll bar" 
(5 cases), "seatbelt" (7 cases), "steering wheel" (1 case), "back seat" (1 case). One patient was a bystander hit and killed by an ROV when the operator inadvertently accelerated. This case was excluded from analysis.

\section{Person-related variables}

Demographic variables included patient sex, age, race, seating position (operator, passenger), and helmet and/ or seatbelt use. Ages were grouped as $<16$ (youth) and $\geq 16$ years (adult). Other person-related variables were whether the operator tested positive or negative for alcohol use. Drug/medication use was defined as operators testing positive for illicit drugs (e.g. amphetamines) or reporting use of prescription or over the counter (OTC) medications.

For helmet use, the narrative was searched for the word "helmet." For seatbelts, the narrative was searched using variations on the word "seatbelt" (8 cases). In addition, there were 52 cases where the narrative was consistent with the victim being unrestrained, e.g. the mechanism included being ejected/falling off the vehicle or the victim was found outside/under the vehicle. The narrative was also used to determine whether there was adult supervision of youth operators.

\section{Crash-related variables}

Crash-related variables included the year, the season (coded as Winter (Dec-Feb), Spring (Mar-May), Summer (Jun-Aug), and Fall (Sep-Nov)), and the day of the week grouped as Weekday (Mon-Fri) or Weekend (Sat-Sun). Crash location was coded as on roadways or off-road based on location-related variables. Light conditions were coded as Day, Dawn (30 min before sunrise), Dusk (30 min before sunset), and Night. For bivariate analyses, comparisons were made for Day vs. Night.

The mechanism was coded as a collision with another motor vehicle or an object, or as a non-collision event, either an ejection/fall from the vehicle or a rollover. For bivariate comparisons, crashes were categorized as collision or non-collision events. Narratives were used to determine whether the victim was trapped/pinned under the vehicle. Crashes were also coded as whether they involved multiple victims. Vehicle use was a trauma record coded variable termed work-related. Estimated speeds were extracted from patient notes and grouped as $\leq 20$ $\mathrm{mph}$ and $>20 \mathrm{mph}$.

\section{Outcome variables}

Clinical outcomes included the Glasgow Coma Scale (GCS) value at emergency department (ED) presentation. GCS scores were grouped as normal (15) or abnormal $(<15)$ and by severity; GCS 13-14 (minor), 9-12 (moderate), or severe $(<8)$. Whether the patient had experienced loss of consciousness (LOC) was also noted.
The maximum abbreviated injury severity (MAIS) score was used to determine whether there was an injury to the head, face, chest, abdomen, extremities, and/or external (skin). MAIS values of 0 were coded as "No" and $>0$ as "Yes." A major trauma was defined as an overall injury severity score (ISS) of $>15$. Other injuryrelated characteristics included whether the patient was admitted to the hospital, admitted to the intensive care unit (ICU), was endotracheally intubated and ventilated, and/or died because of their injuries.

\section{Data analysis}

Descriptive (frequency) and bivariate (chi-square, Fishers Exact test) analyses were performed using IBM SPSS Statistics. Missing data were not included in analysis. Statistical significance for bivariate analysis was defined as a two-sided $p$-value of $<0.05$. Linear regression analysis of the data was performed to determine the trendline of the number of ROV victims over time. The $\beta$ (slope), $r^{2}$ (correlation coefficient) and $p$-value were determined.

\section{Results}

\section{Person-related characteristics}

From 2004 to 2017, 72 patients from 67 crashes presented to the trauma center with injuries as an operator or passenger in an ROV. Patient ages ranged from 4 to 88 years with $49 \%$ being youth < 16 years old, and $64 \%$ were $\leq 25$ years old (Table 1 ). Almost two-thirds (63\%) of patients were male, and $99 \%$ were Caucasian. Approximately half (48\%) were operators and half (52\%) passengers. Less than $10 \%$ were belted. Among those adults with alcohol test results $(n=23)$, more than twofifths $(43 \%)$ tested positive. Only one patient (a 17-yearold male) was documented as wearing a helmet at the time of the crash. Where supervision of child operators $<16$ years old was documented $(7 / 10,70 \%)$, two cases had adult supervision and five were unsupervised.

\section{Crashes}

The number of patients increased over the study period (Fig. 1). The highest proportions of victims were in ROV crashes occurring during the summer months and on weekdays (Table 2). Nearly $30 \%$ of crashes were on public roads. Around one in five occurred at night. Twothirds of victims were injured in a rollover. The second most common mechanism was an ejection/fall from the vehicle. Crash narratives indicated almost two-fifths of victims had at least some part of their body pinned under the ROV, including the ROPS. Four patients were injured while working. Where speed was documented (36/67, 64\%), 61\% were injured in crashes at speeds of $\leq$ $20 \mathrm{mph}$. 
Table 1 Person-related variables for recreational off-highway vehicle (ROV) crash patients presenting to a Level 1 trauma center from 2004 to 2017

\begin{tabular}{ll}
\hline Group N & $\mathrm{n}(\mathrm{Col} \%)^{\mathrm{a}}$ \\
\hline Sex & 72
\end{tabular}

Sex

$$
\begin{aligned}
& \text { Male } \\
& \text { Female } \\
& \text { Age } \\
& <16 \text { years } \\
& \geq 16 \text { years }
\end{aligned}
$$

Race

Caucasian

Other

Seating

Operator

Passenger

Belted

Yes

No

Alcohol results

Positive

Negative

Drug/medication use

None documented

Illicit

Prescription

Over the counter

${ }^{\mathrm{a}}$ The sum of $\mathrm{n}$ may not equal the total Group $\mathrm{N}$ due to missing values

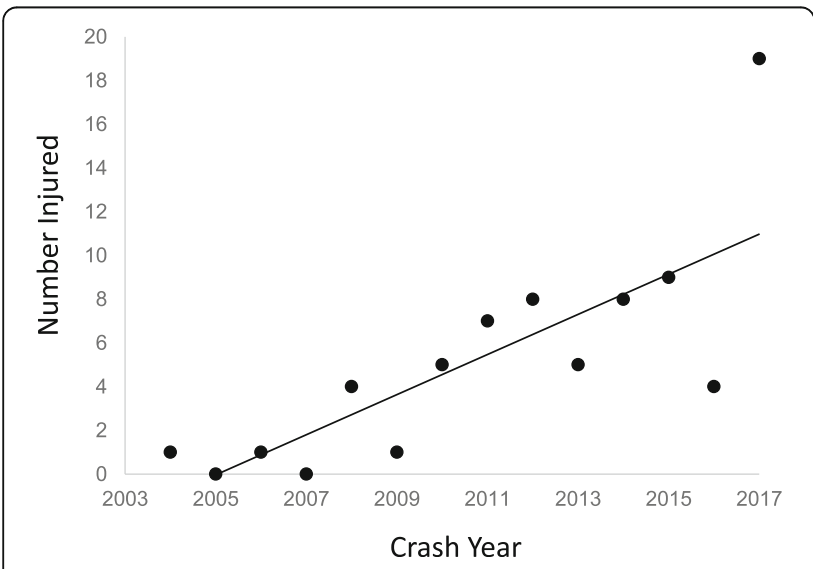

Fig. 1 ROV Crash Patients 2004-2017. Graph of the number of ROV crash victims presenting to an academic Level 1 trauma center as a function of crash year. The trendline from linear regression analysis of the data is shown. Results include: $\beta$ (slope) $=0.95$ (indicating an average increase of approximately " 1 " in the number injured per year), $r^{2}$ (correlation coefficient) $=0.62$ (a value defined as a strong correlation), and $p$-value $=0.0008$
Table 2 Crash-related variables for recreational off-highway vehicle (ROV) crash patients presenting to a Level 1 trauma center from 2004 to 2017

\begin{tabular}{ll}
\hline Group N & $\mathrm{n}(\mathrm{Co} / \%)^{\mathrm{a}}$ \\
\hline Seas
\end{tabular}

Season

$\begin{array}{ll}\text { Winter (Dec-Feb) } & 4(6 \%) \\ \text { Spring (Mar-May) } & 22(31 \%) \\ \text { Summer (Jun-Aug) } & 34(47 \%) \\ \text { Fall (Sep-Nov) } & 12(17 \%)\end{array}$

Day of Week

Weekday (Mon-Fri) 51 (71\%)

Weekend (Sat-Sun) $21(29 \%)$

Crash Location

Roadway

$12(29 \%)$

Off-road

$30(71 \%)$

Light

Day

$50(79 \%)$

Dawn/Dusk

$2(3 \%)$

Night

$11(18 \%)$

Injury Mechanism

ROV-ROV Collision 1 (1\%)

ROV-MV Collision $3(4 \%)$

ROV-Object Collision $6(8 \%)$

$48(67 \%) \quad$ Ejection/Fall $13(18 \%)$

$2(3 \%) \quad$ Rollover $\quad 48(67 \%)$

15 (21\%) Pinned

Yes $26(37 \%)$

No

$45(63 \%)$

Work-Related

Yes $4(6 \%)$

No $\quad 60(94 \%)$

Speed

$\leq 20 \mathrm{mph} \quad 22(61 \%)$

$>20 \mathrm{mph} \quad 14$ (39\%)

The sum of $\mathrm{n}$ for a variable may not equal the total Group $\mathrm{N}$ due to missing data

\section{Outcomes}

Around 10\% of patients had an abnormal GCS score < 15 (Table 3). Additionally, six had severe brain injuries $(\mathrm{GCS}<8)$, and 19 suffered a loss of consciousness. Based on MÄIS scores, one-fourth of victims suffered a head injury and over half suffered an injury to the extremities and/or externally to the skin. Major trauma (ISS > 15) was observed in $13 \%$ of victims. Almost three-quarters of patients were admitted to the hospital, $26 \%$ were admitted to the ICU, and $10 \%$ were ventilated. About half of those admitted to the ICU (48\%) had an ICU length 
Table 3 Characteristics of recreational off-highway vehicle (ROV) related crash outcomes among patients presenting to a Level 1 trauma center from 2004 to 2017

\begin{tabular}{|c|c|}
\hline & $\mathrm{n}(\mathrm{Col} \%)^{\mathrm{a}}$ \\
\hline Group N & 72 \\
\hline \multicolumn{2}{|c|}{ Glasgow coma scale } \\
\hline 15 & $63(89 \%)$ \\
\hline$<15$ & $8(11 \%)$ \\
\hline \multicolumn{2}{|l|}{ Head injury ${ }^{b}$} \\
\hline Yes & $13(24 \%)$ \\
\hline No & $42(76 \%)$ \\
\hline \multicolumn{2}{|l|}{ Face injury ${ }^{b}$} \\
\hline Yes & $11(20 \%)$ \\
\hline No & $44(80 \%)$ \\
\hline \multicolumn{2}{|l|}{ Chest injury ${ }^{b}$} \\
\hline Yes & $12(22 \%)$ \\
\hline No & $43(78 \%)$ \\
\hline \multicolumn{2}{|c|}{ Abdominal injury ${ }^{b}$} \\
\hline Yes & $6(11 \%)$ \\
\hline No & $49(89 \%)$ \\
\hline \multicolumn{2}{|c|}{ Extremity injury ${ }^{\mathrm{b}}$} \\
\hline Yes & $32(58 \%)$ \\
\hline No & $23(42 \%)$ \\
\hline \multicolumn{2}{|c|}{ External (skin) injury ${ }^{b}$} \\
\hline Yes & $28(51 \%)$ \\
\hline No & 27 (49\%) \\
\hline \multicolumn{2}{|c|}{ Injury severity score } \\
\hline$\leq 15$ & $63(87 \%)$ \\
\hline$>15$ & $9(13 \%)$ \\
\hline \multicolumn{2}{|l|}{ Disposition } \\
\hline Admitted & $53(74 \%)$ \\
\hline Discharged & $19(26 \%)$ \\
\hline \multicolumn{2}{|c|}{ Intensive care unit } \\
\hline Yes & $19(26 \%)$ \\
\hline No & $53(74 \%)$ \\
\hline \multicolumn{2}{|l|}{ Ventilated } \\
\hline Yes & $7(10 \%)$ \\
\hline No & 65 (90\%) \\
\hline
\end{tabular}

${ }^{a}$ The sum of $\mathrm{n}$ may not equal the total Group $\mathrm{N}$ due to missing values ${ }^{\mathrm{b}}$ Based on maximum abbreviated injury severity (MAIS) score; $0=$ no injury, $>0=$ injury

of stay of three or more days. Three patients died (two adults, one youth 6 years old).

\section{Males versus females}

Comparisons by sex showed females were a higher proportion of youth victims $<16$ years old than they were of those $\geq 16$ years $(p=0.03)$ (Table 4$)$. Additionally, relative to males, females were a smaller percentage of patients injured on weekends $(p=0.02)$. No other sex-dependent differences in variables were observed. The patterns and severity of injuries for males and females were also similar (Table 5), with about one-quarter suffering head injuries. Two-thirds of females and almost $80 \%$ of males were hospitalized for their injuries. Other results for sexbased comparisons included the observation that $90 \%$ of victims testing positive for alcohol were male. Three of the four persons suffering work-related injuries were also male.

\section{Youth versus adults}

A higher percentage of youth were passenger victims compared to those $\geq 16$ years $(p<0.01)$ (Table 4$)$. Still, $30 \%$ of youth victims were operators of the vehicle. Additionally, compared to $39 \%$ of adult patients being injured at night, no victims $<16$ years old were in nighttime crashes $(p<0.01)$. Seat belt use by both youth and adults was very low. Similarly to adults, youth were most often injured in the summer and during the week. More than a quarter of youth were injured in a roadway crash, and over $80 \%$ of their crashes involved a non-collision event. About a third of youth victims were pinned by the vehicle, and two-thirds of crashes occurred at estimated speeds $\leq 20 \mathrm{mph}$.

Injury patterns among youth were similar to adults (Table 5). A quarter of youth suffered injuries to the head and/or face, with one-half or more having extremity or external (skin) injuries. Two-thirds of children were hospitalized. All occupational-related ROV crashes $(n=4)$ and patients testing positive for alcohol $(n=10)$ were adults.

\section{Other comparisons}

Except for the seating differences by age, no differences in crash characteristics and outcomes were observed when comparing operators and passengers. There was a higher percentage of victims testing positive for alcohol on weekends $(6 / 8,75 \%)$, as compared to weekdays $(4 / 15$, $27 \%)(p=0.04)$. All eight victims with an abnormal GCS were unrestrained, were hospitalized in the ICU, and seven of the eight were mechanically ventilated. Those pinned by the vehicle were more commonly ventilated $(5 / 26,19 \%)$ than those who were not $(1 / 45$, $2 \%)(p=0.02)$. Pinned victims were also more commonly admitted $(23 / 26,88 \%)$ than those not trapped by the vehicle $(29 / 45,64 \%)(p<0.05)$.

\section{Discussion}

Our study characterized the demographics, crash mechanisms, and clinical outcomes for ROV crash victims 
Table 4 Bivariate analyses of demographics and crashes by sex and by age for victims in recreational off-highway vehicle (ROV) related crashes presenting to a Level 1 trauma center from 2004 to 2017

\begin{tabular}{|c|c|c|c|c|c|c|}
\hline & \multicolumn{3}{|l|}{ Sex } & \multicolumn{3}{|l|}{ Age } \\
\hline & $\begin{array}{l}\text { Male } \\
\text { n (Col \%) }\end{array}$ & $\begin{array}{l}\text { Female } \\
\mathrm{n}(\mathrm{Col} \%)^{\mathrm{a}}\end{array}$ & $p$ value & $\begin{array}{l}<16 \text { Years } \\
\mathrm{n}(\mathrm{Col} \%)^{\mathrm{a}}\end{array}$ & $\begin{array}{l}\geq 16 \text { Years } \\
\bar{n}(\mathrm{Col} \%)^{a}\end{array}$ & $p$ value \\
\hline Group N & 45 & 27 & & 35 & 37 & \\
\hline \multicolumn{7}{|l|}{ Age } \\
\hline$<16$ years & $17(38 \%)$ & $18(67 \%)$ & 0.03 & & & \\
\hline$\geq 16$ years & $28(62 \%)$ & $9(33 \%)$ & & & & \\
\hline \multicolumn{7}{|l|}{ Seating } \\
\hline Operator & $24(55 \%)$ & $10(38 \%)$ & 0.22 & $10(30 \%)$ & $24(65 \%)$ & 0.005 \\
\hline Passenger & $20(45 \%)$ & $16(62 \%)$ & & $23(70 \%)$ & $13(35 \%)$ & \\
\hline \multicolumn{7}{|l|}{ Belted } \\
\hline Yes & $1(3 \%)$ & $4(17 \%)$ & 0.15 & $4(13 \%)$ & $1(3 \%)$ & 0.36 \\
\hline No & 35 (97\%) & $20(83 \%)$ & & 27 (87\%) & $28(97 \%)$ & \\
\hline \multicolumn{7}{|l|}{ Season } \\
\hline Winter (Dec-Feb) & $2(4 \%)$ & $2(7 \%)$ & 0.15 & $0(0 \%)$ & $4(11 \%)$ & 0.19 \\
\hline Spring (Mar-May) & $13(29 \%)$ & $9(33 \%)$ & & $11(31 \%)$ & $11(30 \%)$ & \\
\hline Summer (Jun-Aug) & $19(42 \%)$ & $15(56 \%)$ & & 19 (54\%) & 15 (41\%) & \\
\hline Fall (Sep-Nov) & $11(24 \%)$ & $1(4 \%)$ & & $5(14 \%)$ & $7(19 \%)$ & \\
\hline \multicolumn{7}{|l|}{ Day of Week } \\
\hline Weekday (Mon-Fri) & $27(60 \%)$ & $24(89 \%)$ & 0.02 & $28(80 \%)$ & $23(62 \%)$ & 0.12 \\
\hline Weekend (Sat-Sun) & $18(40 \%)$ & $3(11 \%)$ & & $7(20 \%)$ & $14(38 \%)$ & \\
\hline \multicolumn{7}{|l|}{ Location } \\
\hline Roadway & $7(28 \%)$ & $5(29 \%)$ & 1.0 & $6(26 \%)$ & $6(32 \%)$ & 0.74 \\
\hline Off-Road & $18(72 \%)$ & $12(71 \%)$ & & 17 (74\%) & $13(68 \%)$ & \\
\hline \multicolumn{7}{|l|}{ Light } \\
\hline Day & $29(81 \%)$ & $21(84 \%)$ & 1.0 & 33 (100\%) & 17 (61\%) & $<0.001$ \\
\hline Night & $7(19 \%)$ & $4(16 \%)$ & & $0(0 \%)$ & 11 (39\%) & \\
\hline \multicolumn{7}{|l|}{ Collision } \\
\hline Yes & $6(13 \%)$ & $4(15 \%)$ & 1.0 & $5(14 \%)$ & $5(14 \%)$ & 1.0 \\
\hline No & 39 (87\%) & $23(85 \%)$ & & 30 (86\%) & 32 (86\%) & \\
\hline \multicolumn{7}{|l|}{ Pinned } \\
\hline Yes & 27 (60\%) & 18 (69\%) & 0.61 & 12 (34\%) & 14 (39\%) & 0.81 \\
\hline No & $18(40 \%)$ & $8(31 \%)$ & & $23(66 \%)$ & 22 (61\%) & \\
\hline \multicolumn{7}{|l|}{ Speed } \\
\hline$\leq 20 \mathrm{mph}$ & 12 (57\%) & 10 (67\%) & 0.73 & 12 (67\%) & $10(56 \%)$ & 0.73 \\
\hline$>20 \mathrm{mph}$ & $9(43 \%)$ & $5(33 \%)$ & & $6(33 \%)$ & $8(44 \%)$ & \\
\hline
\end{tabular}

${ }^{\mathrm{a}}$ The sum of $\mathrm{n}$ for a variable may not equal the total Group $\mathrm{N}$ due to missing values

presenting to a Level 1 trauma center over a 14-year study period. Overall, we found youth $<16$ years old were approximately half (49\%) of all victims, rollovers were the major crash mechanism, and personal protective equipment (PPE) was rarely used. Clinical outcomes from these crashes were also relatively severe, with the majority of patients being admitted to the hospital, including $26 \%$ to the ICU.

\section{Recreational off-highway vehicles}

Over the last decade, healthcare providers have noticed an increasing number of ROV-related injuries (Linnaus et al., 2017; Richardson et al., 2018). Between January 2003 and August 2016, 942 ROV crashes involving 665 fatalities and 843 injuries were reported by the U.S. Consumer Product Safety Commission (CPSC) (U.S. Consumer Product Safety Commission, 2016). Another 
Table 5 Bivariate analysis of injuries and outcomes by sex and by age for victims in recreational off-highway vehicle (ROV) related crashes presenting to a Level 1 trauma center from 2004 to 2017

\begin{tabular}{|c|c|c|c|c|c|c|}
\hline & \multicolumn{3}{|l|}{ Sex } & \multicolumn{3}{|l|}{ Age } \\
\hline & $\begin{array}{l}\text { Male } \\
\text { n (Col \%) }\end{array}$ & $\begin{array}{l}\text { Female } \\
\mathrm{n}(\mathrm{Col} \%)^{\mathrm{a}}\end{array}$ & $p$ value & $\begin{array}{l}<16 \text { Years } \\
\mathrm{n}(\mathrm{Col} \%)^{\mathrm{a}}\end{array}$ & $\begin{array}{l}\geq 16 \text { Years } \\
\mathrm{n}(\mathrm{Col} \mathrm{\%})^{\mathrm{a}}\end{array}$ & $p$ value \\
\hline Group N & 45 & 27 & & 35 & 37 & \\
\hline \multicolumn{7}{|l|}{ GCS } \\
\hline 15 & 39 (89\%) & 24 (89\%) & 1.0 & 29 (83\%) & 34 (94\%) & 0.15 \\
\hline$<15$ & $5(11 \%)$ & $3(11 \%)$ & & $6(17 \%)$ & $2(6 \%)$ & \\
\hline \multicolumn{7}{|l|}{ Head injury ${ }^{b}$} \\
\hline Yes & $8(22 \%)$ & $5(26 \%)$ & 0.75 & $6(25 \%)$ & $7(23 \%)$ & 1.0 \\
\hline No & $28(78 \%)$ & 14 (74\%) & & $18(75 \%)$ & $24(77 \%)$ & \\
\hline \multicolumn{7}{|l|}{ Face injury ${ }^{b}$} \\
\hline Yes & $9(25 \%)$ & $2(11 \%)$ & 0.30 & $6(25 \%)$ & $5(16 \%)$ & 0.51 \\
\hline No & 27 (75\%) & 17 (89\%) & & $18(75 \%)$ & $26(84 \%)$ & \\
\hline \multicolumn{7}{|l|}{ Chest injury $^{b}$} \\
\hline Yes & $9(25 \%)$ & $3(16 \%)$ & 0.51 & $4(17 \%)$ & $8(26 \%)$ & 0.52 \\
\hline No & 27 (75\%) & $16(84 \%)$ & & $20(83 \%)$ & $23(74 \%)$ & \\
\hline \multicolumn{7}{|c|}{ Abdominal injury ${ }^{b}$} \\
\hline Yes & $4(11 \%)$ & $2(11 \%)$ & 1.0 & $2(8 \%)$ & $4(13 \%)$ & 0.69 \\
\hline No & 32 (89\%) & 17 (89\%) & & $22(92 \%)$ & 27 (87\%) & \\
\hline \multicolumn{7}{|c|}{ Extremity injury ${ }^{b}$} \\
\hline Yes & $22(61 \%)$ & $10(53 \%)$ & 0.58 & $14(58 \%)$ & $18(58 \%)$ & 1.0 \\
\hline No & $14(39 \%)$ & $9(47 \%)$ & & $10(42 \%)$ & $13(42 \%)$ & \\
\hline \multicolumn{7}{|c|}{ External (skin) injury ${ }^{b}$} \\
\hline Yes & $18(50 \%)$ & 10 (53\%) & 1.0 & $12(50 \%)$ & $16(52 \%)$ & 1.0 \\
\hline No & $18(50 \%)$ & $9(47 \%)$ & & $12(50 \%)$ & $15(48 \%)$ & \\
\hline \multicolumn{7}{|l|}{ ISS } \\
\hline$\leq 15$ & 38 (84\%) & 25 (93\%) & 0.47 & 30 (86\%) & 33 (89\%) & 0.73 \\
\hline$>15$ & $7(16 \%)$ & $2(7 \%)$ & & $5(14 \%)$ & $4(11 \%)$ & \\
\hline \multicolumn{7}{|l|}{ Disposition } \\
\hline Admitted & 35 (78\%) & $18(67 \%)$ & 0.41 & $23(66 \%)$ & 30 (81\%) & 0.18 \\
\hline Discharged & $10(22 \%)$ & $9(33 \%)$ & & 12 (34\%) & $7(19 \%)$ & \\
\hline \multicolumn{7}{|l|}{$\mathrm{ICU}$} \\
\hline Yes & 13 (29\%) & $6(22 \%)$ & 0.59 & $10(29 \%)$ & $9(24 \%)$ & 0.79 \\
\hline No & 32 (71\%) & 21 (78\%) & & 25 (71\%) & 28 (76\%) & \\
\hline \multicolumn{7}{|l|}{ Ventilated } \\
\hline Yes & $5(11 \%)$ & $2(7 \%)$ & 0.70 & $5(14 \%)$ & $2(5 \%)$ & 0.25 \\
\hline No & 40 (89\%) & 25 (93\%) & & 30 (86\%) & 35 (95\%) & \\
\hline
\end{tabular}

Abbreviations GCS Glasgow Coma Scale, ICU Intensive Care Unit, ISS Injury Severity Score

${ }^{a}$ The sum of $\mathrm{n}$ for a variable may not equal the total Group $\mathrm{N}$ due to missing values

${ }^{\mathrm{b}}$ Based on maximum abbreviated injury severity (MAIS) score; $0=$ no injury, $>0=$ injury

study using CPSC and Fatality Analysis Reporting System (FARS) data showed an increase in ROV crashrelated deaths on public roadways in the FARS data from two in 2006 to 37 in 2015 (Richardson et al., 2018).
A study of newspaper articles from nine Midwestern and Great Plains states from 2009 to 2011 reported 79 crashes with 104 victims (Jennissen et al., 2016). Finally, researchers at a pediatric trauma center studying off-road vehicle crashes 
from January 2007 through July 2015 identified 42 patients involved in what they termed UTV crashes, most of which were likely ROVs (Linnaus et al., 2017).

\section{Demographics}

Almost two-thirds of patients in our study were males. This proportion is similar to the 2016 CPSC report (68\%), the 2018 CPSC/FARS study (71\%), and the newspaper article study (70\%) (U.S. Consumer Product Safety Commission, 2016; Richardson et al., 2018; Jennissen et al., 2016). In contrast, the pediatric trauma center study reported males comprised only $55 \%$ of victims (Linnaus et al., 2017). All of these studies, including ours, found a lower proportion of males than is commonly seen for ATVs, where they are typically $>85 \%$ of victims (Denning et al., 2013a; Denning et al., 2013b; Denning et al., 2014; Denning \& Jennissen, 2016).

ROVs are designed for multiple riders. Consistent with this, we found about half of those injured were passengers. The newspaper article study reported passengers were $37 \%$ of victims (Jennissen et al., 2016). In contrast to ROVs, almost all ATVs are designed for an operator only, and previous studies found passengers were about 15-22\% of ATV-related injuries and deaths (Jennissen et al., 2016; Denning et al., 2013a; Denning et al., 2013b; Denning et al., 2014; Denning \& Jennissen, 2016). These ATV studies found injured females were more commonly passengers than were males. This was also true for ROV crashes in the study using newspaper articles: males, $75 \%$ operators, $25 \%$ passengers; females, $43 \%$ operators, $57 \%$ passengers (Jennissen et al., 2016). We saw a similar pattern in our study (Table 4), but the differences did not reach statistical significance.

Children and adolescents appear to be a particularly vulnerable riding population. Nearly one-half $(49 \%)$ of the ROV crash victims in our study were $<16$ years old. This was similar to the newspaper article study showing youth were $44 \%$ of ROV crash victims (Jennissen et al., 2016). In both cases, youth were a considerably higher percentage of victims than that typically reported for ATVs (24-29\%) (Jennissen et al., 2016; Denning et al., 2014; Denning \& Jennissen, 2018). A significantly higher proportion of injured children were passengers (70\%) compared to adults (35\%) in our study. Still, $30 \%$ of child crash victims were drivers of the ROV at the time of their injury. Children < 16 years old were drivers in $21 \%$ of crashes in reports collected by the CPSC where the age of the driver was known, and $14 \%$ of ROV drivers killed on public roads in the FARS database (Richardson et al., 2018).

Manufacturers warn consumers in the owner's manuals (Kawasaki Heavy Industries, 2012; Polaris Industries, n.d.-b) and with vehicle decals that adult-size ROVs should not be driven by anyone $<16$ years old. Manufacturers also recommend that child passengers be at least 12 years old. They state all riders should be able to sit with their backs against the seat with both feet flat on the floor and grip the passenger hand hold (Kawasaki Heavy Industries L, 2012; Polaris Industries, n.d.-b). Unfortunately, many families do not adhere to these recommendations. Sometimes parents will put children in car seats or booster seats in ROVs, but these products have not been tested for use in these vehicles and manufacturers provide no guidance. Greater efforts are needed to educate consumers on the dangers of ROVs and provide safety information on their proper use.

\section{Crash mechanism}

Rollovers were the primary crash mechanism in our study. Other studies have found the majority of ROV crashes (Jennissen et al., 2016; U.S. Consumer Product Safety Commission, 2014), like ATV crashes (Denning et al., 2014; Unni et al., 2012; Humphries et al., 2006), were rollovers. In addition, the CPSC study determined $68 \%$ were lateral rollovers with over one-half occurring during a turn. About $90 \%$ of the most severely injured had been in a rollover, and among rollover crashes for which terrain was known, more than half occurred on flat surfaces. The lateral stability and vehicle handling characteristics of ROVs have been a concern (U.S. Consumer Product Safety Commission, 2016; U.S. Consumer Product Safety Commission, 2014), and efforts to improve their safety engineering and design is very much needed.

\section{Personal protective equipment}

A major contributor to severe injury in ROV crashes is riding unrestrained. Only $8 \%$ of victims presenting to our trauma center appeared to be restrained, very similar to the $6 \%$ of victims documented as being restrained in the newspaper article study (Jennissen et al., 2016). In that same study, nearly three-quarters of those who died had been ejected from the vehicle (Jennissen et al., 2016). In reports using national data, only $14 \%$ of ROV occupants were known to be belted, and half to threequarters of victims who were injured or killed were not wearing a seat belt or harness system (Richardson et al., 2018; U.S. Consumer Product Safety Commission, 2014). The vast majority of these victims were partially or fully ejected from the vehicle. Among pediatric patients with ROV-related injuries, 70\% were not restrained (Linnaus et al., 2017).

We found $37 \%$ of the victims had been pinned by the vehicle. Other studies have shown about one-half or more of those injured were struck or pinned (Jennissen et al., 2016; U.S. Consumer Product Safety Commission, 2014). Nearly $30 \%$ of victims in reports collected by the CPSC were pinned by the vehicle, usually by the ROPS structure (Richardson et al., 2018). ROVs weigh up to a 
1000 pounds. They can transmit significant forces to occupants who are ejected from the vehicle and cannot be easily lifted off a pinned victim. One of the most important factors in decreasing ROV-related injuries and deaths is for occupants to always wear the seat belt or harness system for each and every ride, and there should be no passengers who cannot be properly restrained.

Manufacturers and safety experts recommend the use of helmets when riding in ROVs. Only one patient seen at our trauma center was documented as wearing a helmet, and one-fourth of victims suffered a head injury. In a nine-state study of ROV crashes, three (3\%) were reported as being helmeted (Jennissen et al., 2016), and < $15 \%$ of pediatric victims injured in ROV crashes were wearing helmets, both significantly lower percentages than helmet use on ATVs and dirt bikes (Linnaus et al., 2017). Only $2 \%$ of victims in the CPSC database were documented as being helmeted (Richardson et al., 2018).

\section{Nighttime driving}

Despite ROVs being equipped with headlights, two-fifths of adults were injured in nighttime crashes. This is similar to the proportion of all ROV crashes occurring in compromised light conditions in the newspaper article study (Jennissen et al., 2016). Appreciating terrain changes and identifying obstacles is inevitably more difficult at night. Nighttime ROV driving should be done with extreme caution and avoided if possible. Adult alcohol use is also likely to be playing a factor in many adult ROV crashes at night.

\section{Roadways}

Like ATVs, ROVs are designed for off-road use only and manufacturers strongly warn against roadway riding (Specialty Vehicle Institute of America, n.d.; Recreational Off-Highway Vehicle Association, n.d.-a). For both vehicles, the dangers of riding on the road are largely related to their fundamental vehicle design (Jennissen et al., 2016; Denning \& Jennissen, 2016; Denning \& Jennissen, 2018). Despite the warnings, almost $30 \%$ of crashes in our study occurred on public roadways. This proportion is slightly lower than that found in other studies. Specifically, one-half of crashes in the newspaper articles from nine states (Jennissen et al., 2016) and 43\% of crashes in the CPSC database (Richardson et al., 2018) were on the road. Interestingly, four-fifths of ROV crashes reported in newspapers from nine states (Jennissen et al., 2016) and $82 \%$ of fatal ROV crashes in the FARS (Richardson et al., 2018) occurring on public roads did not involve another motor vehicle. In other words, the vast majority were single vehicle crashes. Similarly, ATV crash studies have shown that over two-thirds of deaths and threefourths of injuries on public roadways do not involve another motorized vehicle (Denning et al., 2013a; Denning et al., 2013b). Because of their design, off-road vehicles including ROVs can have unpredictable interactions with roadway surfaces and should not be driven on public roads.

\section{Clinical outcomes}

Injuries sustained in ROV crashes are often quite severe. In our study, $74 \%$ of patients were hospitalized, including over one-fourth in the ICU, and half of these were youth < 16 years old. A study at a Level 1 pediatric trauma center (2007-2018) identifying 42 ROV crash patients also found high rates of admission to the hospital (79\%) and ICU (27\%) (Linnaus et al., 2017).

\section{Limitations}

Our study was retrospective, had a relatively limited sample size, and involves a single trauma center, which limits its generalizability to other populations. As potential cases for our study were determined by ICD coding, it is possible some ROV cases were not identified due to miscoding and/or missing narrative cues. In addition, narratives where patients were clearly ejected/fell from the vehicle were interpreted as their being unbelted. However, they could also represent improper belt use. Moreover, the need to identify ROVs and code other variables from narratives may introduce documentation bias. Finally, ED populations do not include all fatalities as those occurring pre-hospital are not included in the trauma database. Despite these limitations, ROV-related crashes and injuries are an emerging safety issue about which little has been published, and our findings contribute to this small body of knowledge.

\section{Conclusions}

Although ROVs have rollover protective structures, lack of adherence to manufacturer safety recommendations including helmet and safety belt use and refraining from driving on public roadways is likely reducing their benefit. Almost all ROVs are designed to be driven by those $\geq 16$ years old, and manufacturers recommend passengers be 12 years or older. Our studies support the hypothesis that youth are a vulnerable ROV riding population. Laws as outlined in the Recreational Off-Highway Vehicle Association's model legislation (Recreational Off-Highway Vehicle Association, n.d.-b) should be adopted and strictly enforced. Increased public education and anticipatory guidance by healthcare providers on ROV safety are also greatly needed. Given the increasing popularity and prevalence of these vehicles, ROV crashes and injuries should be considered an emerging public health concern and multi-pronged strategies should be developed to prevent these serious injuries. 


\section{Abbreviations}

AIS: Abbreviated Injury Score; ATV: All-terrain vehicle; ED: Emergency department; GCS: Glasgow Coma Scale; ISS: Injury Severity Score; LOC: Loss of consciousness; LOS: Length of stay; MAIS: Maximum Abbreviated Injury Score; MV: Motor vehicle; ROV: Recreational off-highway vehicle; SPSS: Statistics Package for the Social Sciences; SxS: Side-by-side; UTV: Utility task vehicle

\section{Acknowledgements}

We would like to acknowledge Joshua Godding, MD, and Curtis Brown, MD, who assisted with variable coding and database management. We would also like to acknowledge Kristel Wetjen for her assistance in identifying potential cases in the University of lowa Trauma Registry.

\section{About this supplement}

This article has been published as part of Injury Epidemiology Volume 7 Supplement 1, 2020: Proceedings from the 24th Annual Injury Free Coalition for Kids ${ }^{\circledR}$ Conference: Forging New Frontiers: Motor Vehicle Safety for All Ages. The full contents of the supplement are available online at https://injepijournal. biomedcentral.com/articles/supplements/volume-7-supplement-1.

\section{Authors' contributions}

Each author significantly contributed to and takes public responsibility for one or more aspects of the study. Specifically: CJ had primary responsibility for study design and interpretation of the data. He also wrote the manuscript and had primary responsibility for its final form and submission. MR organized and cleaned the data. She also participated in analysis and interpretation of the data and assisted in writing the manuscript. GD primarily analyzed the data and organized the results. She also helped in the interpretation of the data and in writing of the manuscript. All authors have read and approved the final manuscript.

\section{Funding}

Support for this study was provided by the Department of Emergency Medicine at the University of lowa. Publication charges were funded by the Injury Free Coalition for Kids ${ }^{\mathrm{TM}}$. Both of these entities had no specific role in the research performed.

\section{Availability of data and materials}

Data and materials are available to other parties for research purposes after a data sharing agreement plan is agreed to and signed.

\section{Ethics approval and consent to participate}

The University of lowa Institutional Review Board approved this study. Consent to participate was not needed or applicable due to the study being a retrospective review.

\section{Consent for publication}

Not applicable.

\section{Competing interests}

The authors declare that they have no competing interests or financial relationships relevant to this article to disclose.

Published: 12 June 2020

\section{References}

Denning G, Harland K, Ellis D, Jennissen C. More fatal all-terrain vehicle crashes occur on the roadway than off: increased risk-taking characterises roadway fatalities. Inj Prev. 2013a;19:250-6.

Denning G, Harland K, Jennissen C. Age-based risk factors for pediatric ATVrelated fatalities. Pediatrics. 2014;134(6):1094-102.

Denning G, Jennissen C. Pediatric and adolescent injury in all-terrain vehicles. Special issue: epidemiology of youth injury in adventure and extreme sports. Res Sports Med. 2018;26(S1):38-56 Guest edited by: Caine DJ, Provance AJ.

Denning G, Jennissen C, Harland K, Ellis D, Buresh C. All-terrain vehicles (ATVs) on the road: a serious traffic safety and public health concern. Traffic Inj Prev 2013b;14(1):78-85.

Denning GM, Jennissen CA. All-terrain vehicle fatalities on paved roads, unpaved roads, and off-road: evidence for informed roadway safety warnings and legislation. Traffic Inj Prev. 2016;17(4):406-12.
Humphries RL, Stone CK, Stapczynski JS, Florea S. An assessment of pediatric allterrain vehicle injuries. Pediatr Emerg Care. 2006:22(7):491-4.

Jennissen C, Harland K, Denning G. Characteristics of side-by-side vehicle crashes and related injuries as determined using newspaper reports from nine U.S. States. Safety. 2016;2(2) Available at: http://www.mdpi.com/2313-576X/2/2/1 0. Accessed 30 Dec 2019

Kawasaki Heavy Industries. Mule 4010 Trans4x4 Utility Vehicle Owner's Manual. 2012. Available at: http://www.manualslib.com/manual/803081/KawasakiMule-4010-Trans-4x4.html?page=7\#manual Accessed 30 Dec 2019.

Linnaus ME, Ragar RL, Garvey EM, Fraser JD. Injuries and outcomes associated with recreational vehicle accidents in pediatric trauma. J Pediatr Surg. 2017; 52(2):327-33 Epub 14 Sept 2016

Polaris Industries. Polaris 2015-2018 Annual reports. n.d.-a. Available at: http:// www.annualreports.com/Company/polaris-industries. Accessed 30 Dec 2019.

Polaris Industries. Polaris RZR 1000 EPS 2019 Owner's Manual. n.d.-b. Available at: https://www.manualslib.com/manual/1513963/Polaris-Rzr-Xp-1000-Eps-2019. html\#product-RZR XP 1000 EPS 2019. Accessed 30 Dec 2019.

Recreational Off-Highway Vehicle Association. Position in opposition to onhighway operation of ROVs. n.d.-a. Available at: https://rohva.org/wpcontent/uploads/2019/02/ROVOn-HwyPositionPaper.pdf Accessed 30 Dec 2019.

Recreational Off-Highway Vehicle Association. Model state recreational offhighway vehicle legislation. n.d.-b. Available at: https://rohva.org/wp-content/ uploads/2019/02/ROV_Model_Summary_12-11.pdf Accessed 30 Dec 2019.

Richardson RE, McMurry TL, Gepner B, Kerrigan JR. Field data analysis of recreational off-highway vehicle crashes. Traffic Inj Prev. 2018;19(6):623-8.

Specialty Vehicle Institute of America. SVIA position in opposition to on-road operation of ATVs. n.d.. Available at: https://svia.org/wp-content/uploads/201 7/12/SVIAOnRoadOppositionPosition-2016.pdf Accessed 30 Dec 2019.

U.S. Consumer Product Safety Commission. Notice of Proposed Rulemaking. 16 CFR Part 1422. Safety standard for recreational off-highway vehicles (ROVs). Fed Regist. 2014;79(223):68964-9031 Available at: https://www.govinfo.gov/ content/pkg/FR-2014-11-19/pdf/2014-26500.pdf Accessed 30 Dec 2019.

U.S. Consumer Product Safety Commission. Evaluation of Voluntary Standards for Recreational Off-Highway Vehicles (ROVs). 2016. Available at: https://www. cpsc.gov/s3fs-public/ RecreationalOffHighwayVehiclesTerminationofRulemaking.pdf Accessed 30 Dec 2019.

Unni P, Morrow SE, Shultz B. Analysis of pediatric all-terrain vehicle trauma data in middle Tennessee: implications for injury prevention. J Trauma Acute Care Surg. 2012;73(4 Suppl 3):S277-80.

Wilson L. Side-by-side off-road vehicles: rollover occupant protection-standards and vehicle classification. In: Winter meeting of the ANB45(1) Rollover subcommittee sponsored by the ANB45 Occupant Protection committee of the Transport Research Board; 2015. Available at: https://drive.google.com/ file/d/OB6SQ53ha-ZVDMWQ3cU9WOW9CQ3c/view. Accessed 30 Oct 2015.

\section{Publisher's Note}

Springer Nature remains neutral with regard to jurisdictional claims in published maps and institutional affiliations.
Ready to submit your research? Choose BMC and benefit from:

- fast, convenient online submission

- thorough peer review by experienced researchers in your field

- rapid publication on acceptance

- support for research data, including large and complex data types

- gold Open Access which fosters wider collaboration and increased citations

- maximum visibility for your research: over $100 \mathrm{M}$ website views per year

At BMC, research is always in progress.

Learn more biomedcentral.com/submissions 